that a condition indistinguishable from it could be produced by some other cause. These ideas were very adversely and, we think, unfairly criticised, and now, after the lapse of nearly a year, appear to be receiving considerable confirmation. - We are, Sirs, yours faithfully,

W. A. NEWALL, M.D., Ch.B. Vict.

J. R. Prхтневoh, M.B., Ch. B. Edin., M.R.C.S. Eng., Oct. 28th, 1901. L. R.C.P. Lond.

\section{THE NEEDS OF THE ROYAL LONDON OPHTHALMIC HOSPITAL (MOORFIELDS).}

To the Editors of THE LANCET.

SIRs,-A year has now passed since the governors of the Royal London Ophthalmic Hospital were summoned for rates. At that time, thanks to the publicity given to the case, both by the London and by the provincial press, many friends sent prompt and generous help enabling the committee to meet this demand, and the rates were fully paid. The committee, have now, however, to face a similar demand, and this at a time when they are seriously hampered in their endeavours to meet the ordinary expenses of the hospital, by reason of the calls on the charitable public of other and more national demands. We, therefore, beg you to help them by making known to the public the very grave position of this great charity.

The committee had hoped that during the last session of Parliament an Act would have been passed to relieve hospitals, wholly or in part, from rates, but, although the Select Committee appointed by the House of Commons made their report as far back as July, 1900, there has been up to the present no legislation on the subject. The report called attention to the numerous anomalies existing in the rating of hospitals, some of which are exempted from rates by local statutes, while many have been treated with the greatest consideration by the rating authorities. On the other hand, the rates are a heavy burden to some hospitals, but few are so terribly crippled-by them as the Royal London Ophthalmic Hospital, which is still compelled to keep half its beds closed, and although last year the annual subscriptions amounted to $£ 1096$, out of these rates and taxes to the extent of $£ 896$ had to be paid. This year the hospital has already paid $£ 700$ on this account, and now a further demand is made for £250. The local rating authorities say they cannot lower the assessment, and point out as one reason that this great hospital does not exist for the relief of the district or even of the City alone, but receives patients from every part of the kingdom. Therefore, the committee appeal to all for help to enable this national charity to tide over a pressing emergency.

Donations and annual subscriptions may be paid to Williams Deacon's Bank Limited, 20, Birchin-lane, E.C., or to the Secretary at the Hospital. We are. Sirs, yours faithfully,

AVEBURY President.

H. P. STUkGis,

Chairman of the Committee of Management, Hy. DAVISON

Chairman of the Finance Committee.

Royal London Ophthalmic Hospital (Moorfields Eye Hospital), City-road, E.C., Oet. 29th, 1901.

\section{"ACUTE DILATATION OF THE STOMACH}

\section{To the Editors of THE LANCET.}

SIRS,-The following remarks may be of interest in "connexion with the paper on Acute Dilatation of the Stomach, with Illustrative Cases, read before the Royal Medical and Chirurand with the report of the discussion which appeared in gical Society on Oct. 2nd by Dr. H. Campbell Thomson THE LANCET. ${ }^{2}$ Acute gaseous dilatation is of frequent occurrence, often associated with agonising pain and with a feeling of impending death, yet not fatal. In cases of this sort there is po permanent obstruction; usually unaccompanied by vomiting they tend to be relieved by it when it does occur. In them the pain is due to the excessive pressure of gastric inflation superadded to the normal or to an increased volume of intestinal gas, and the abdomen is enlarged, but to a great extent into the thorax. Fatal cases such as are brought forward by Dr. Thomson differ from them in all those particulars. The pain is not acute, vomiting does not relieve, the abdominal distension is not necessarily considerable or may be almost absent, the gastric distension makes for the abdomen rather than for the thorax, and the intestine is almost airless. Death occurs from the exhaustion of vomiting rather than from pressure. These are essentially cases of obstruction.

As noted by Dr. Thomson, the dilated stomach is bent at an angle, and, as I have repeatedly demonstrated in the post-mortem room, not only the pyloric portion, but the first part of the duodenum, is apt to take a sharply ascending direction, and the pancreas is also made to slope. 'The mechanism of the distension is obscure, and although in both groups we may admit a large element of disturbed innervation we are still unable to determine where the gas or the fluid may come from. But the mechanism of the fatal obstruction is capable of explanation and sometimes of relief, at least in a section of the cases. That in these the pylorus is not the seat of absolute obstruction is almos proved by the circumstance, urged by Dr. Voelcker in the discussion on the paper. that bile is vomited: it is entirely proved, as in Dr. Thomson's Case No. 2, by the fact that the first portion of the duodenum is distended as well as the stomach. As to Dr. Thomson's other cases, it may perbaps be allowable to suppose, in the absence of any statement to the contrary and on the strength of definite observations made in other instances, that in them the duodenum may have been in an analogous condition. Collateral evidence of the absence of pyloric stricture is afforded by the 10 cases which he tabulates, 3 only one of which presented pyloric disease (described as "narrowing the orifice"), whilst in the remainder no abdominal lesion was found except in two cares where the disease was in the vicinity of the duodenum. The combination of a collapsed intestine and of a distended first part of the duodenum, as in Dr. Thomson's Case No. 2, sufficiently localises the obstruction. The latter is found, as was shown by Rokitansky, and later by Glénard, Kundrat, Schnitzler, Albrecht, and others, at the junction of the jejunum with the transverse portion of the duodenum; this is strangled by the weight of the collapsed intestine which drags the mesentery, and particularly the superior mesenteric artery, as a cord over it According to this view the collapse of the intestine, howsoever produced, whether from marasmus or more often from shock or exhaustion, is the primary event and not the resul of compression by a dilated stomach, and obstructive gastric distension follows. As mentioned by P. A. Albrecht, whose exhaustive essay in Virchow's Archiv ${ }^{4}$ was referred to in a joint communication made by $\mathrm{Mr}$. F. Jaffrey and myself to the Harveian Society of London " " on a case of uncontrollable vomiting relieved by laparotomy and manipulation, and due to the pressure of an aneurysm," the individual length of the mesentery is one of the etiological factors. Intestinal collapse further elongates it so as to allow the intestine, particularly in women, to drop like a dead weight permanently into the pelvis. It is unnecessary that I should dwell upon the other factors and upon the various views which have been advanced, having given a brief account of them in the remarks appended to the paper just mentioned.

This anatomical explanation is probably applicable, with variations, to most cases, and in particular to those which occur after operations involving profound anæsthesia and shock, and to those which arise apparently spontaneously after relatively trivial complications, where the subjects are predisposed to enteroptosis by the original length of their mesentery and by previous malnutrition and exhaustion. I have suggested that in some of the mysterious ca-es of socalled "hysterical or neurotic" type, with advanced emaciation and prostration, the persistent vomiting may be kept up by analogous conditions independently of any major gastric dilatation.

The treatment of this form of obstruction is suggested by its cause. The stretched meventery must be relieved by raising the intestine from the pelvic trough. The rational cure for the visceral malposition and the resulting gastric dilatation is posture. The knee and elbow position advocated by Albrecht may not often be available owing to

$$
\text { * Loc. cit.. p. } 1115 .
$$

4 Ueber Arterio-Mesenterialen Darmverschluss an der DuodenoJejunalgrenze und seine ursächliche Beziehung zur Magenerweiterung (with bibliography). Virchow's Archiv, Band clvi., Hett 2, 1899. 